\title{
Corticospinal function studied over time following incomplete spinal cord injury
}

\author{
HC Smith $^{1}$, G Savic ${ }^{2}$, HL Frankel ${ }^{2}$, PH Ellaway ${ }^{1}$, DW Maskill ${ }^{1}$, MA Jamous ${ }^{2}$ and NJ Davey*,1 \\ ${ }^{1}$ Division of Neuroscience \& Psychological Medicine, Imperial College School of Medicine, Charing Cross Hospital, \\ London W6 8RF, UK; ${ }^{2}$ National Spinal Injuries Centre, Stoke Mandeville Hospital, Aylesbury, Bucks HP21 8AL, \\ $U K$
}

\begin{abstract}
Study design: Longitudinal.
Objectives: (1) To perform standard clinical neurological examinations and establish the pattern of clinical change with time following incomplete spinal cord injury (iSCI). (2) To establish the pattern of change in corticospinal electrophysiological function with time after iSCI. (3) To correlate clinical with electrophysiological findings.

Setting: The National Spinal Injuries Centre, Stoke Mandeville Hospital, Aylesbury, UK and Imperial College School of Medicine, Charing Cross Hospital, London, UK.

Methods: Neurological assessments and classification were performed according to American Spinal Injuries Association and International Medical Society of Paraplegia (ASIA/IMSOP) standards. Twenty-one patients (ages $18-72$ years) with iSCI (level C2-C7, ASIA impairment grades $\mathrm{C}-\mathrm{D}$ ) and 10 healthy control subjects (ages 27-57 years) were studied. Electrophysiological tests of corticospinal function were carried out using transcranial magnetic stimulation (TMS) of the motor cortex and electromyographic (EMG) recordings from thenar muscles. Both tests were performed on a number of occasions, beginning 19-384 days and ending 124-1109 days post-injury, and the group data were pooled into time epochs of 50 or 100 days post-injury for analysis. Seven of the patients were studied on seven or more occasions and were also assessed individually.

Results: Individual and pooled data indicated that neurological scores improved progressively and tended to stabilise by around 300 days post-injury. When the patients were first assessed, the mean latency for motor evoked potentials (MEPs) and inhibition of voluntary EMG were significantly different from control values. There was no significant change in latency on subsequent sessions for either the grouped or individual patient data. There was no correlation between clinical assessment and electrophysiological data.

Conclusion: We conclude that the weakened inhibition seen following iSCI is established within a few days of the time of spinal cord trauma. We argue that reduced corticospinal inhibition may be a prerequisite for the recovery of useful motor function.

Sponsorship: The work was supported by a project grant from The Wellcome Trust. Spinal Cord (2000) 38, $292-300$
\end{abstract}

Keywords: incomplete spinal cord injury; neurological assessment; corticospinal physiology

\section{Introduction}

Neurological examination ${ }^{1}$ of individuals with incomplete spinal cord injury (iSCI) has shown that patients have some propensity for recovery of function with $82 \%$ improving by at least one Frankel grade. ${ }^{2}$ Electrophysiological evaluation of corticospinal continuity can be performed by examining the motor evoked potentials (MEPs) in response to either electrical $^{3}$ or transcranial magnetic stimulation (TMS)

*Correspondence: NJ Davey, Department of Sensorimotor Systems, Division of Neuroscience \& Psychological Medicine, Imperial College School of Medicine, Charing Cross Hospital, Fulham Palace Road, London W6 8RF, UK of the motor cortex (see for example ${ }^{4}$ ). Assessment of threshold and latency of MEPs has supported ${ }^{5-7}$ the results of the clinical neurological examination. However, the use of these techniques in predicting neurological outcome is uncertain ${ }^{6}$ and the standard neurological examination remains the choice for assessing status and probable outcome following spinal cord injury.

We have previously reported changes in corticospinal function in iSCI patients, as revealed by examination of the electromyographic (EMG) responses to transcranial magnetic stimulation (TMS) of the motor cortex, ${ }^{8,9}$ which have a cortical 
component. Specifically we have found a reduction in corticospinal inhibition ${ }^{8,10}$ and a changed pattern of corticospinal facilitation and recruitment. ${ }^{9}$ An early component of the inhibition of voluntary EMG in response to TMS is absent or reduced in iSCI. ${ }^{8} \mathrm{We}$ know from work in normal $\operatorname{man}^{10}$ that at least some of this inhibition is produced via activation of cortical inhibitory interneurones by TMS, which turn off cortical output. We interpret the reduction of inhibition seen in $\mathrm{iSCI}^{8}$ as an adaptation following spinal cord injury directed towards increasing descending drive in surviving corticospinal neurones. We have used proton magnetic resonance spectroscopy (MRS) of the motor cortex to demonstrate an elevated level of the neuronal metabolite $\mathrm{N}$-acetylaspartate (NAA), supporting the notion of cortical reorganisation following iSCI. ${ }^{11}$ Our preliminary work using positron emission tomography (PET) has indicated a reduced presence of the inhibitory neurotransmitter gamma aminobutyric acid (GABA) in the motor cortex after iSCI ${ }^{12}$ supporting the electrophysiological indications of reduced cortical inhibition.

It is clearly relevant to know whether the changes in corticospinal electrophysiology are simply a result of the injury or whether they may predispose or facilitate the recovery of function seen following iSCI. To this end we have studied the corticospinal physiology in 21 patients with incomplete cervical spinal lesions over a 3-year period following injury. The results of the electrophysiological investigations were correlated with neurological assessments performed during the same period. Preliminary results of this study have been published in abstract form. ${ }^{13}$

\section{Methods}

Patients and control subjects

Ethical approval for this study was obtained from the Aylesbury Vale local research ethics committee and the Riverside Research Ethics Committee. All subjects gave their written consent, in accordance with the declaration of Helsinki. Ten control subjects (two men, eight women) aged 27-57 years (mean age 40.1) with no history of neurological disease, took part in the study. Twenty-one patients (18 men, three women) with incomplete spinal cord lesions above the level of C8 (level of innervation of tested muscles) aged 18-72 years (mean age 45.6) recruited from the National Spinal Injuries Centre, Stoke Mandeville Hospital participated in the study. Clinical details for each patient are given in Table 1.

\section{Timing of assessments}

Neurological assessment and electrophysiological testing were both carried out on a number of occasions post-injury in each patient. The patient data were grouped into time epochs according to the time elapsed

Table 1 Details of patients included in the study. Patients 15-21 (indicated by *) were monitored individually as well as contributing to the pooled data. Neurological grades of patients are given at the time of admission [1], the first electrophysiological test [2] and the last electrophysiological test [3]

\begin{tabular}{|c|c|c|c|c|c|c|c|c|c|}
\hline Patient & $\begin{array}{c}\text { Age } \\
\text { (years) }\end{array}$ & $\begin{array}{c}\text { Gender } \\
(m / f)\end{array}$ & $\begin{array}{l}\text { Cause } \\
(t / n t)\end{array}$ & $\begin{array}{c}\text { Duration } \\
\text { at admission } \\
\text { (days) [1] }\end{array}$ & $\begin{array}{c}\text { Duration } \\
\text { at first test } \\
\text { (days) }[2]\end{array}$ & $\begin{array}{c}\text { Duration } \\
\text { at last test } \\
\text { (days) }[3]\end{array}$ & $\begin{array}{c}\text { Neurological } \\
\text { level }\end{array}$ & $\begin{array}{c}A S I A \\
\text { grade } \\
{[1 / 2 / 3]}\end{array}$ & $\begin{array}{c}\text { Anti- } \\
\text { spasticity } \\
\text { medication }\end{array}$ \\
\hline 1 & 67 & $\mathrm{~m}$ & $\mathrm{t}$ & 120 & 158 & 269 & $\mathrm{C} 5$ & $\mathrm{C} / \mathrm{C} / \mathrm{C}$ & nil \\
\hline 2 & 66 & $\mathrm{~m}$ & $\mathrm{t}$ & 9 & 74 & 324 & C5 & $\mathrm{D} / \mathrm{D} / \mathrm{D}$ & nil \\
\hline 3 & 26 & $\mathrm{~m}$ & $\mathrm{t}$ & 8 & 124 & 244 & C5 & $\mathrm{B} / \mathrm{C} / \mathrm{C}$ & $\mathrm{ba} / \mathrm{dant}$ \\
\hline 4 & 19 & $\mathrm{~m}$ & $\mathrm{t}$ & 34 & 151 & 213 & C6 & $\mathrm{C} / \mathrm{C} / \mathrm{C}$ & dant \\
\hline 5 & 24 & $\mathrm{~m}$ & $\mathrm{t}$ & 22 & 109 & 192 & $\mathrm{C} 5$ & $\mathrm{~B} / \mathrm{C} / \mathrm{C}$ & dant \\
\hline 6 & 34 & $\mathrm{~m}$ & $\mathrm{t}$ & 1 & 71 & 460 & C6 & $\mathrm{C} / \mathrm{C} / \mathrm{D}$ & $\mathrm{ba} / \mathrm{dant}$ \\
\hline 7 & 67 & $\mathrm{~m}$ & $\mathrm{t}$ & 36 & 46 & 128 & $\mathrm{C} 3$ & $\mathrm{C} / \mathrm{C} / \mathrm{D}$ & ba \\
\hline 8 & 35 & $\mathrm{~m}$ & $\mathrm{t}$ & 8 & 68 & 243 & $\mathrm{C} 5$ & $\mathrm{~A} / \mathrm{C} / \mathrm{D}$ & $\mathrm{ba} / \mathrm{dant}$ \\
\hline 9 & 28 & $\mathrm{~m}$ & $\mathrm{t}$ & 216 & 236 & 460 & $\mathrm{C} 4$ & $\mathrm{C} / \mathrm{D} / \mathrm{D}$ & nil \\
\hline 10 & 64 & $\mathrm{~m}$ & $\mathrm{t}$ & 66 & 134 & 254 & C7 & $\mathrm{D} / \mathrm{D} / \mathrm{D}$ & $\mathrm{ba} /$ dant \\
\hline 11 & 28 & $\mathrm{~m}$ & $\mathrm{t}$ & 21 & 114 & 421 & $\mathrm{C} 4$ & $\mathrm{D} / \mathrm{D} / \mathrm{D}$ & ba \\
\hline 12 & 18 & $\mathrm{~m}$ & $\mathrm{t}$ & 29 & 69 & 585 & $\mathrm{C} 7$ & $\mathrm{D} / \mathrm{D} / \mathrm{D}$ & nil \\
\hline 13 & 67 & $\mathrm{f}$ & $\mathrm{t}$ & 34 & 130 & 223 & $\mathrm{C} 2$ & $\mathrm{C} / \mathrm{C} / \mathrm{C}$ & nil \\
\hline 14 & 49 & $\mathrm{~m}$ & $\mathrm{t}$ & 4 & 68 & 124 & $\mathrm{C} 5$ & $\mathrm{D} / \mathrm{D} / \mathrm{D}$ & nil \\
\hline $15^{*}$ & 57 & $\mathrm{f}$ & $\mathrm{t}$ & 44 & 95 & 359 & $\mathrm{C} 4$ & $\mathrm{C} / \mathrm{D} / \mathrm{D}$ & nil \\
\hline $16^{*}$ & 72 & $\mathrm{~m}$ & $\mathrm{t}$ & 3 & 19 & 277 & $\mathrm{C} 4$ & $\mathrm{C} / \mathrm{C} / \mathrm{D}$ & nil \\
\hline $17^{*}$ & 49 & $\mathrm{~m}$ & $\mathrm{t}$ & 19 & 91 & 662 & C5 & $\mathrm{C} / \mathrm{D} / \mathrm{D}$ & nil \\
\hline $18^{*}$ & 46 & $\mathrm{~m}$ & $\mathrm{t}$ & 1 & 51 & 1109 & $\mathrm{C} 4$ & $\mathrm{C} / \mathrm{C} / \mathrm{D}$ & $\mathrm{ba} / \mathrm{dant}$ \\
\hline $19 *$ & 29 & $\mathrm{~m}$ & $\mathrm{t}$ & 9 & 33 & 917 & C5 & $\mathrm{C} / \mathrm{C} / \mathrm{D}$ & ba \\
\hline $20 *$ & 72 & f & $\mathrm{nt}$ & 55 & 384 & 1006 & $\mathrm{C} 4$ & $\mathrm{~B} / \mathrm{D} / \mathrm{D}$ & nil \\
\hline $21 *$ & 41 & $\mathrm{~m}$ & $\mathrm{t}$ & 15 & 77 & 994 & C5 & $\mathrm{C} / \mathrm{D} / \mathrm{D}$ & nil \\
\hline
\end{tabular}

$\mathrm{m}=$ male, $\mathrm{f}=$ female, $\mathrm{t}=$ traumatic, $\mathrm{nt}=$ non-traumatic, $\mathrm{ba}=$ baclofen, dant $=$ dantrolene, ASIA $=$ American Spinal Injury Association 
since injury: Four 50-day time epochs during the first 200 days post-injury and three 100-day time epochs over the next 300 days. A final epoch was constructed containing data from patients taken 501-1200 days after injury. If a patient was examined more than once during a particular time epoch, then average values for that patient were included in the pooled data. Mean values in each time epoch were then established for both neurological and electrophysiological data.

Seven patients (Table 1, nos. 15-21) were assessed on more than seven occasions over a long time-span following injury. This made it possible to plot neurological and physiological data from these patients independently against time after injury.

\section{Neurological examination}

Neurological function was assessed by a physician according to the International Standards for Neurological and Functional Classification of Spinal Cord Injury. Motor function of 10 key muscles was assessed on each side of the body. These included the finger flexors at the distal phalanx of the middle (third) digit for level $\mathrm{C} 8$ and the abductor of the little (fifth) digit for level T1. A score ranging from $0-5$ was awarded for each muscle, with a score of 0 representing no detectable contraction and a score of 5 for normal muscle strength. An overall motor score out of a possible 100 (100 indicating normal motor function) was derived.

Sensory function was assessed on both sides of the body for light touch (principally testing posterior columns) and pin prick (principally testing spinothalamic pathways) sensation over the 28 dermatomes from $\mathrm{C} 2$ to $\mathrm{S} 4 / 5$. At each level a score of 2 was given for normal sensation, 1 for impaired sensation, and 0 for no sensation. As a result, a maximum score of 112 was available for each test.

Neurological level was determined as the most caudal spinal segment with normal sensory and motor function. Each patient was classified according to the American Spinal Injury Association (ASIA) impairment grading; from grade A (neurologically complete) through to grade $\mathrm{E}$ (normal).

\section{Electromyographic (EMG) recordings}

Electromyograms (EMGs) were recorded from the thenar muscles using self-adhesive surface electrodes (Arbo Neonatal Pink). The thenar eminence consists of the following muscle groups: adductor pollicis (innervated by the ulnar nerve), abductor pollicis brevis and opponens pollicis (innervated by the median nerve) and flexor pollicis brevis (innervated by both the median and ulnar nerves). Surface EMG recordings from the thenar eminence would therefore potentially record components of electrical activity from each of these muscles.

When the symptoms were lateralised, the recordings were made from the worst affected side, otherwise the dominant hand was used (all patients right-handed). On this basis, recordings were made from the right thenar muscles in 15 patients and nine control subjects and from the left in six patients and one control subject.

The thenar muscles were palpated by the investigator while the subject attempted to make repeated voluntary contractions. This process helped to identify the area of skin covering the largest bulk of muscle and one electrode was placed in this region. The second electrode was placed away from muscle over the proximal phalanx of the thumb. A metal plate covered with conductive jelly was strapped to the forearm to act as an earth electrode. Subjects were seated comfortably in either an arm-chair or their wheelchair.

EMG signals were filtered $(-3 \mathrm{~dB}$ below $300 \mathrm{~Hz}$ and above $2 \mathrm{kHz})$ and amplified $(\times 1000)$ before being sampled $(4 \mathrm{kHz})$ by a computer for analysis (Cambridge Electronic Design 1401/IBM-compatible PC) and recorded on a digital audio tape (DAT) recorder (Teac, RD 130-T).

Motor evoked potential (MEP) responses to transcranial magnetic stimulation (TMS) were recorded both while relaxed and while the subjects maintained a weak voluntary isometric contraction in their thenar muscles of approximately $5 \%$ to $10 \%$ of their maximum voluntary contraction (MVC). Inhibition of voluntary EMG was recorded using TMS below threshold for eliciting a MEP. Subjects were provided with audio (loudspeaker) and visual (cathode ray oscilloscope) feedback of their EMG signals to enable them to keep their muscles at rest or at a constant level of activity during the study.

\section{Transcranial magnetic stimulation (TMS)}

Electromagnetic stimulation of the brain was achieved using a 2 Tesla Magstim 200 stimulator (MagStim Company) connected to a circular $9 \mathrm{~cm}$ (average diameter) stimulating coil centred over the vertex. Cross-wires were taped to either side of the stimulating coil to facilitate its accurate placement. The position of the vertex on the scalp of each subject was identified as the point midway between the two tragi and midway between the nasion and inion. The coil was positioned (one or other side up) appropriately so that the induced current in the brain flowed in the required direction ${ }^{14}$ to activate the right or left thenar muscles (clockwise for right-hand muscles and anti-clockwise for left-hand muscles as viewed from above). The stimulus intensity was adjusted to a level that evoked a MEP on $50 \%$ of stimulus presentations with the thenar muscles relaxed. This intensity was expressed as percentage of maximum stimulator output ( $\%$ MSO) and designated as 'threshold'. ${ }^{15}$ This procedure was repeated for MEPs and inhibition with the muscles voluntarily contracted to $5 \%$ to $10 \%$ MVC. 
Signal averaging and measurement of motor responses to TMS

Unrectified and full-wave rectified EMG signals were averaged, with reference to the time of the stimulus, using Cambridge Electronic Design signal averaging software (SIGAVG). The latency of the MEP response was measured from the averaged rectified records with the muscles relaxes and during periods of weak voluntary contraction.

The latency of inhibition ${ }^{10}$ was measured from the stimulus to the point in the record where the EMG fell consistently below mean background levels. The presence or absence of inhibition was assessed by eye and if there was no identifiable decrease in background EMG after averaging the responses from 50 stimuli, the stimulus intensity was deemed to be below threshold for inhibition. Weak, infrequent excitatory responses within the variable on-going EMG of a voluntary contraction may not be rectified about a true zero reference level and may be missed or even be misinterpreted as inhibition. ${ }^{16}$ We therefore also examined averages of unrectified EMG traces to ensure that a period of inhibition was not preceded by a small facilitatory response.

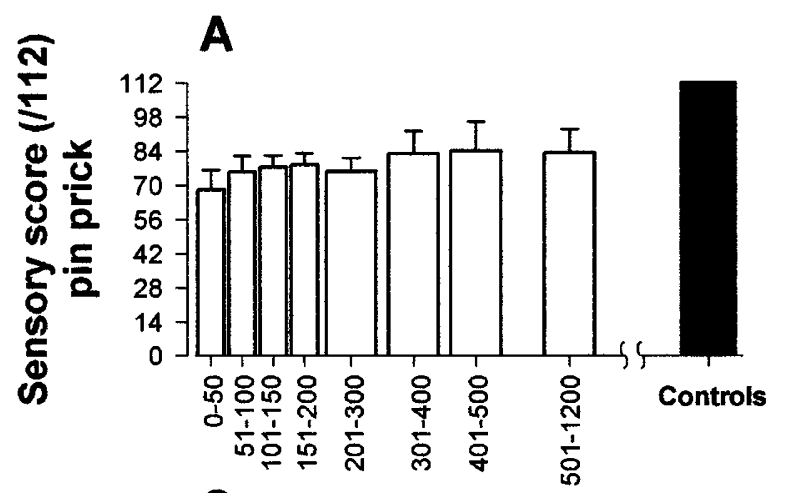

B

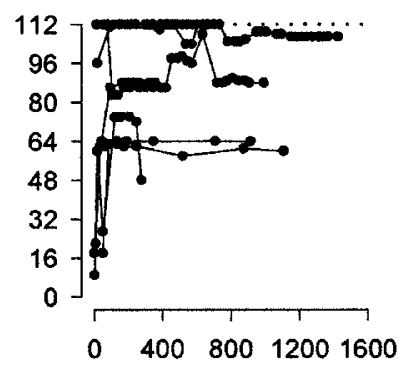

D
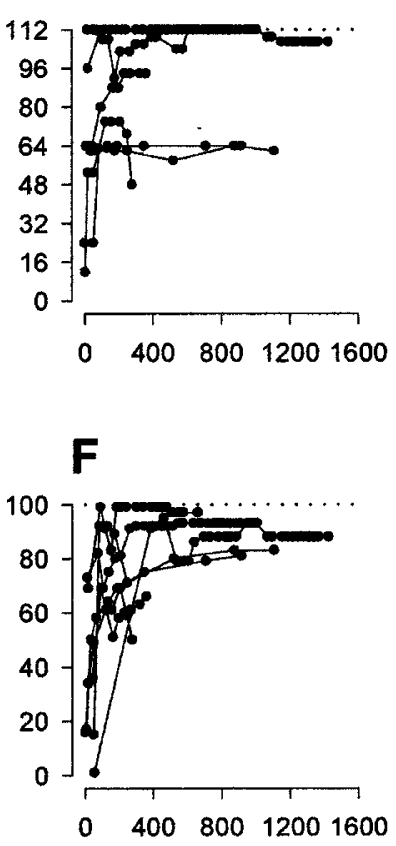

Time post-injury (days)

Figure 1 Neurological scores at different times following injury. Pooled data for different time epochs are plotted for sensory score (pin-prick) (A), sensory score (light touch) $(\mathbf{C})$ and motor score $(\mathbf{E})$. Solid bars indicate normal values. Error bars indicate 1 standard error of the mean. The asterisk indicates significant $(P<0.05)$ difference between adjacent time epochs. Data for seven individual patients (Table 1 , nos. 15-21) are plotted for sensory score (pin-prick) (B), sensory score (light touch) (D) and motor score $(\mathbf{F})$. Horizontal dotted lines indicate normal values 


\section{Statistical analysis}

Electrophysiological data in each time epoch were compared with the control population using a Bonferoni $t$-test. Adjacent time epochs for clinical neurological data and electrophysiological data were compared using a Bonferoni $t$-test. Trends in the neurological and electrophysiological data with time were examined using Pearson product moment correlation. Differences were considered significant if probability of the null hypothesis was less than $5 \%$.

\section{Results}

\section{Neurological assessments}

Table 1 summarises the ASIA grades for each patient on admission [1], at the time of the first electrophysiological test [2] and at the time of the last electrophysiological test [3]. The duration of injury on each of these occasions is given.

On admission one patient had ASIA grade A, three had grade B, 12 had grade $\mathrm{C}$ and five had grade D. By the time of the final electrophysiological test the group status had improved to five patients with ASIA grade $\mathrm{C}$ and 16 with grade D.

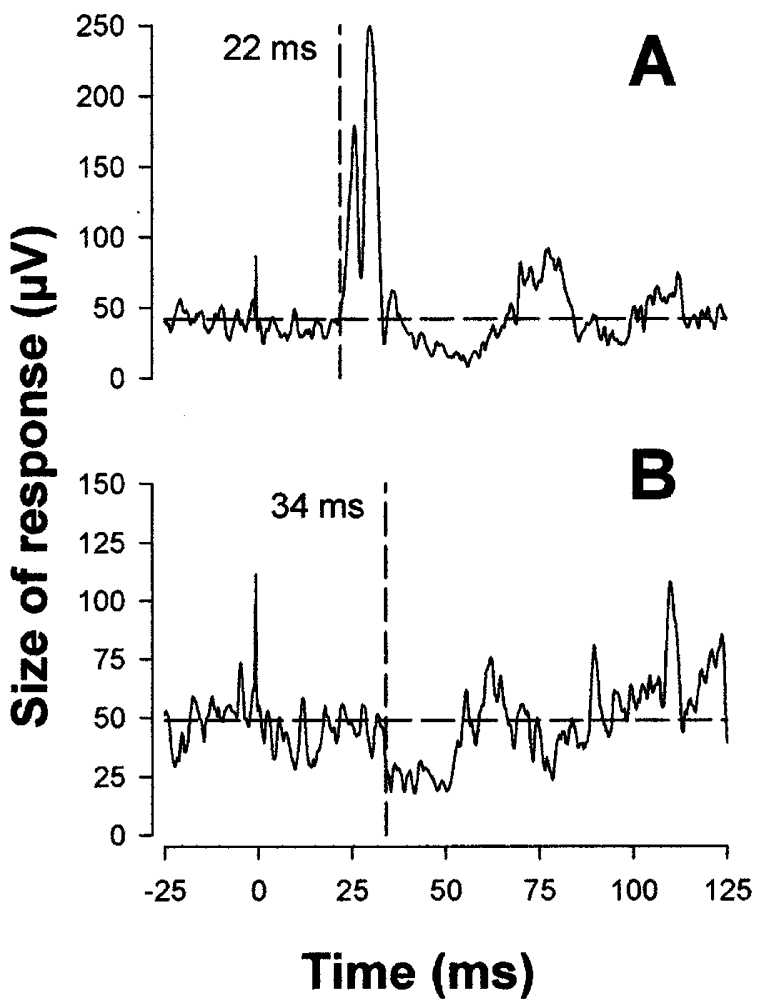

Sensory (pin-prick and light touch) and motor scores are shown graphically in Figure 1 for the grouped data from all 21 patients (Figure 1A, C, E) as well as for the seven patients studied individually (Figure 1B, D, F). The group data showed significant improvement in mean $( \pm$ SE) motor score from $41 \pm 5.7$ at 50 days after injury to $62 \pm 6.3$ after 100 days. Examination of Figure 1 shows that individual motor scores and mean group data continued to improve during the first 300-400 days after injury (Figure 1E, F) before stabilising.

\section{Electrophysiological assessments}

Averaged rectified EMG responses to TMS from a control subject and a patient are shown in Figure 2 while the individuals made a weak voluntary contraction of the thenar muscles. The threshold TMS intensity required to evoke a MEP was $36 \% \mathrm{MSO}$ in the control (Figure 2A) and 50\% MSO in the patient (Figure 2C) and to evoke inhibition was $30 \% \mathrm{MSO}$ in the control (Figure 2B) and 40\% MSO in the patient (Figure 2D). The latency of the MEP was $22 \mathrm{~ms}$ in the control and $28 \mathrm{~ms}$ in the patient while the latency of inhibition was $34 \mathrm{~ms}$ in the control and $50 \mathrm{~ms}$ in the patient.

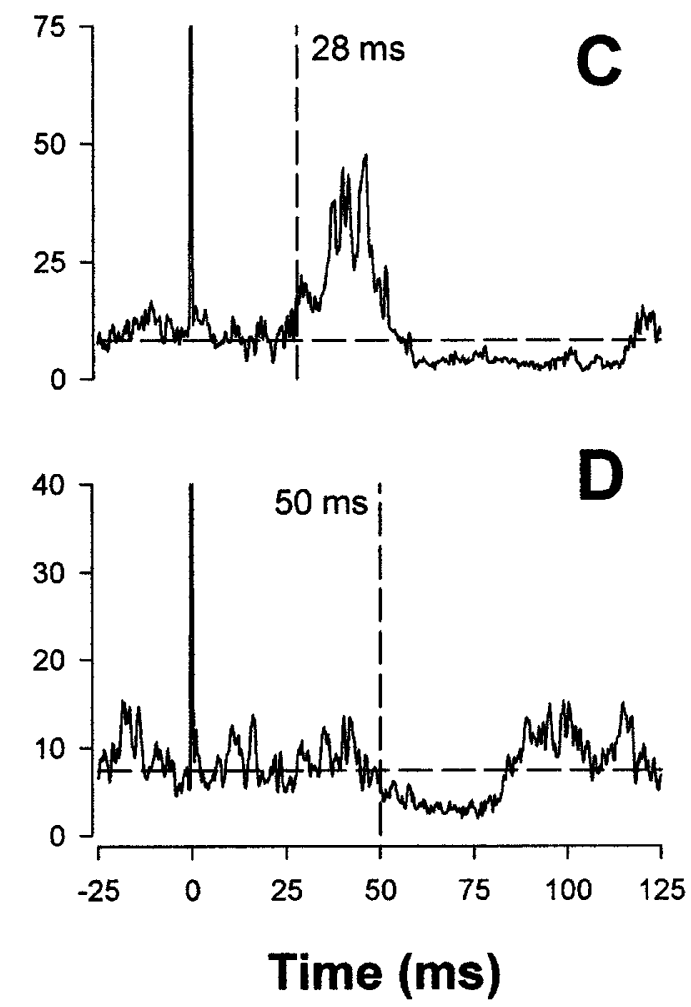

Figure 2 Rectified and averaged EMG responses of thenar muscles to TMS of the motor cortex in a control subject (A, B) and a patient $(\mathbf{C}, \mathbf{D}$; Table 1, no. 21) recorded during weak voluntary contraction. $(\mathbf{A}, \mathbf{C})$ are examples of MEPs and $(\mathbf{B}, \mathbf{D})$ are examples of inhibition. The records have been rectified and then averaged $(\times 15(\mathbf{A}, \mathbf{C})$ or $\times 50(\mathbf{B}, \mathbf{D}))$. Stimulus strengths were (A) 36\% MSO, (B) 30\% MSO, (C) 50\% MSO, (D) 40\% MSO. Note the longer latency and higher threshold of the MEP and inhibition in the patient 
Mean $( \pm$ SE) grouped data for threshold TMS in the patients were consistently higher than control values for MEPs with the muscle relaxed controls, $40 \pm 2.8 \%$ MSO; patients at, for example, 51-100 days, $56 \pm 4.3 \% \mathrm{MSO}$; see Figure $3 \mathrm{~A}$ ) or contracted (controls, $32 \pm 1.6 \%$ MSO; patients at 51-100 days, $39 \pm 3.1 \%$ MSO; see Figure 3C) and for inhibition (controls, $27 \pm 1.3 \%$ MSO; patients at 51-100 days, $39 \pm 3.5 \%$ MSO; see Figure 3E). Individual patient values (Figure 3B, D, F) showed, for the most part, higher thresholds for MEPs in both relaxed and contracted muscles and for inhibition. There was no trend in the data with time after injury and thresholds remained higher than control throughout the period of investigation but achieving significance in only four epochs at rest and one during contraction $(201-300$ days, $45 \pm 3.8 \%$ MSO). The threshold for inhibition was significantly higher than control values in the $0-50$ day time epoch and remained significantly elevated up to day 500 . In the final time epoch (501-1200 days) the mean remained elevated $(36 \pm 4.8 \%$ MSO $)$ although not significantly so but this epoch contained data from only six patients and variability was high.

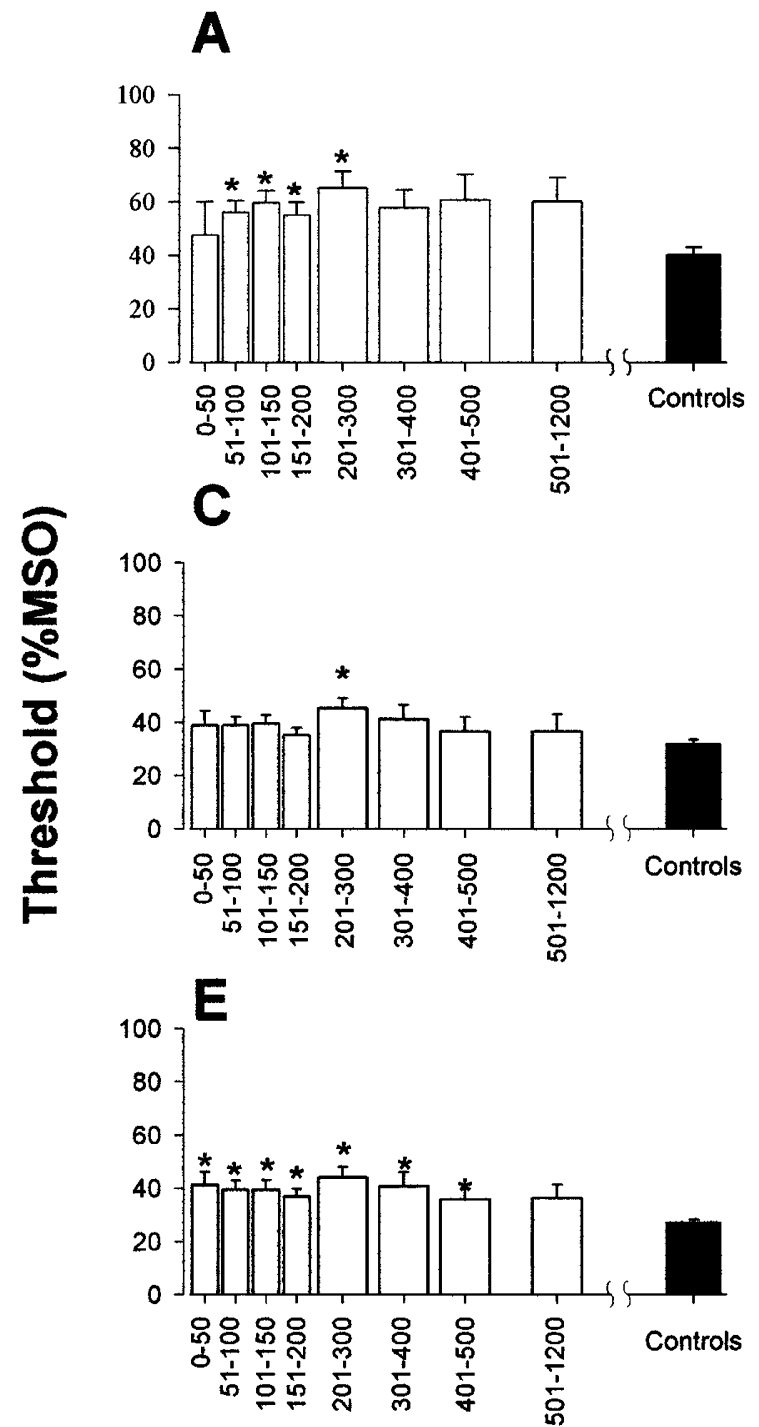

Time post-injury (days)
B

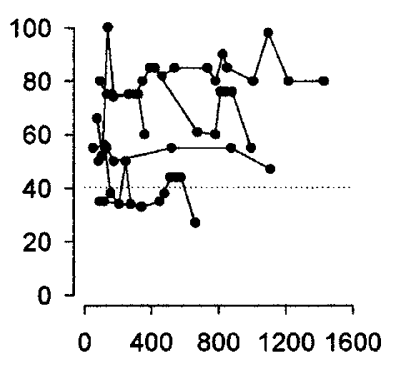

D
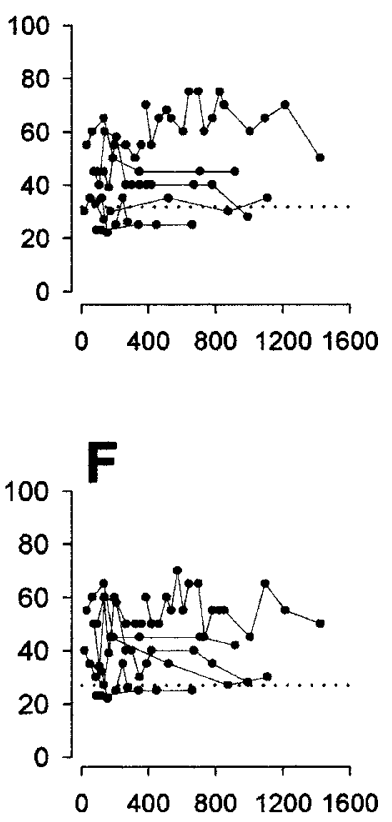

Time post-injury (days)

Figure 3 TMS threshold for MEPs and inhibition at different times following injury. Pooled data for different time epochs are plotted for MEPs (muscles relaxed) (A), MEPs (muscle contracted) (C) and inhibition (E). Solid bars indicate control values. Error bars indicate 1 standard error of the mean. Asterisks indicate significant $(P<0.05)$ difference from control values. Data for seven individual patients (Table 1, nos. 15-21) are plotted for MEPs (muscles relaxed) (B), MEPs (muscles contracted) (D) and inhibition $(\mathbf{F})$. Horizontal dotted lines indicate control values 

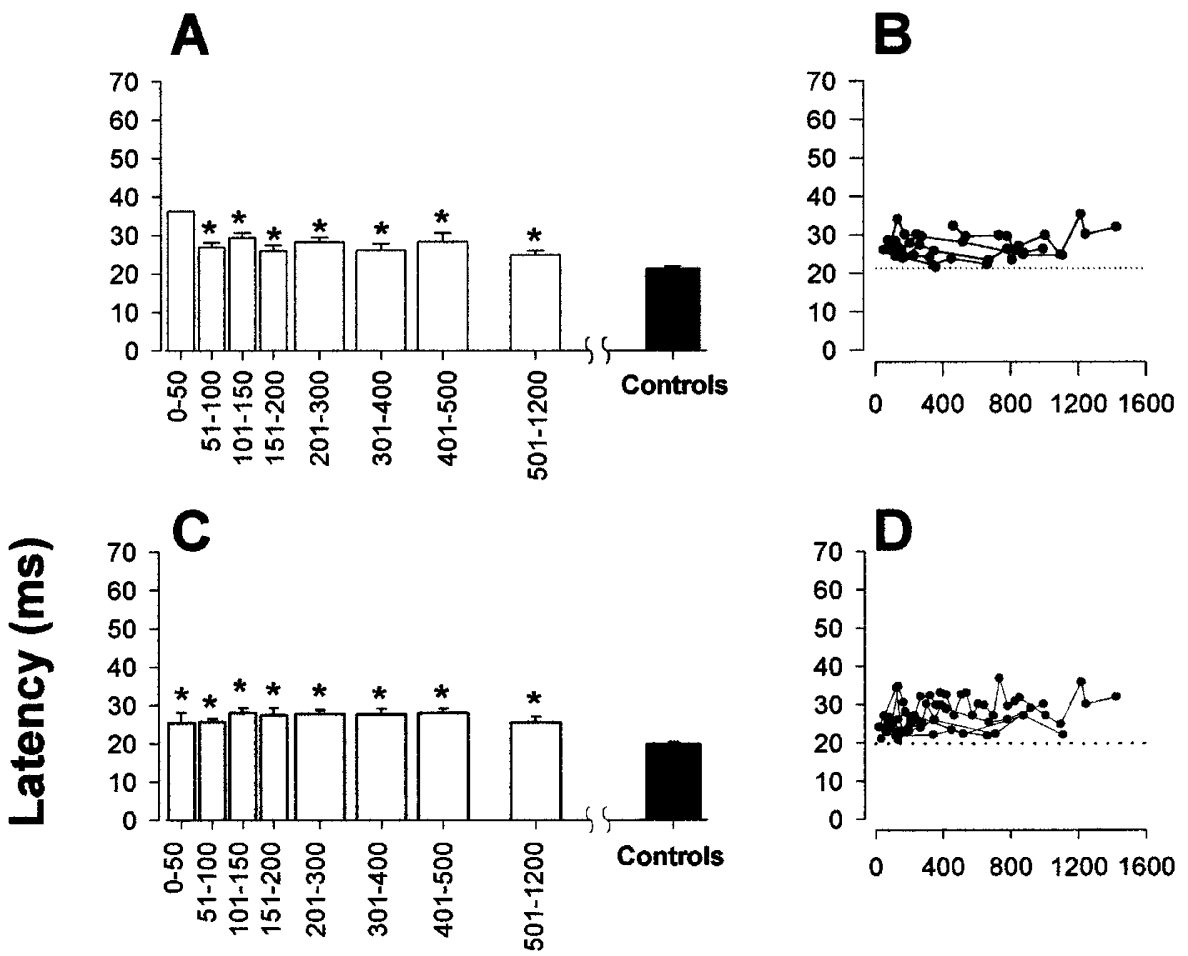

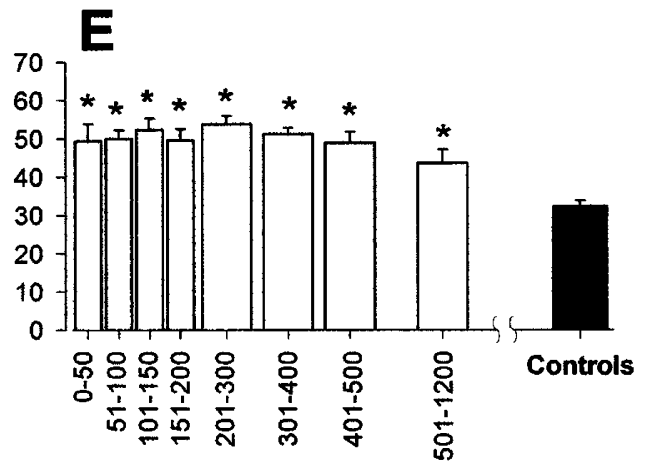

Time post-injury (days)

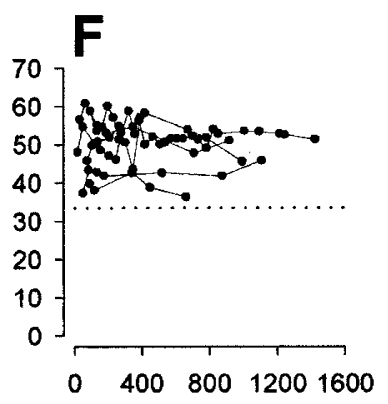

Time post-injury (days)

Figure 4 Response latency for MEPs and inhibition at different times following injury. Pooled data for different time epochs are plotted for MEPs (muscles relaxed) (A), MEPs (muscle contracted) (C) and inhibition (E). Solid bars indicate control values. Error bars indicate 1 standard error of the mean. Asterisks indicate significant $(P<0.05)$ difference from control values. Data for seven individual patients (Table 1, nos. 15-21) are plotted for MEPs (muscles relaxed) (B), MEPs (muscles contracted) (D) and inhibition (F). Horizontal dotted lines indicate control values

Mean $( \pm \mathrm{SE})$ grouped data and individual values for latency of MEPs with the muscle relaxed (controls, $21 \pm 0.6 \mathrm{~ms}$; patients at, for example, 51-100 days, $27 \pm 1.2 \mathrm{~ms}$; see Figure 4A, B) or activated (controls, $20 \pm 0.5 \mathrm{~ms}$; patients at $51-100$ days, $26 \pm 0.8 \mathrm{~ms}$; see Figure 4C, D) and of inhibition (controls, $32 \pm 1.5 \mathrm{~ms}$; patients at $51-100$ days, $50 \pm 2.2 \mathrm{~ms}$, see Figure 4E, F) were longer than control values throughout the period of study. Note that the $0-50$ day time epoch for MEP latencies in the relaxed muscle (Figure 4A) does not achieve statistical significance as it contains data from only one patient (latency $36 \mathrm{~ms}$ ). As with thresholds, there was no trend in the data with time after injury and latencies were longer than controls throughout the period of study. The mean latency of inhibition did get slightly shorter in the final time epoch $(501-1200$ days; $44 \pm 3.4 \mathrm{~ms}$ ) but only six patients contributed to the data.

There was no significant correlation over time between motor score and either the threshold or latency of MEPs or inhibitory responses.

In summary, there was some improvement in both mean grouped and individual neurological scores for motor and sensory function during the first year or so after injury. In particular, there was significant improvement of motor function between 50 and 100 
days after injury. Thresholds and latencies of MEPs and inhibition were consistently higher than control values but did not change significantly with time after injury. There was no correlation between motor score and any electrophysiological parameter.

\section{Discussion}

The standard clinical neurological tests ${ }^{1}$ used in this study have demonstrated that iSCI patients make some recovery of motor and sensory function which is progressive over the first year following injury and only reaches a relatively stable level thereafter. In contrast, the electrophysiological measures of corticospinal function are depressed following iSCI but show no significant signs of recovery, remaining relatively stable over the period of investigation. The differences from normal in thresholds and latency of $\mathrm{MEPs}^{8}$ probably reflect damage to the descending corticospinal neurones mediating the response to $\mathrm{TMS}^{17}$ rather than cortical changes. If this is the case then reversion towards normal values will depend not on neuronal reorganisation but rather on restoration of conduction in damaged descending axons. Any such changes may occur early in the post-injury period, before the time of our first electrophysiological investigation.

The most striking difference in corticospinal function following iSCI is a reduced cortical inhibition $^{10}$ as evidenced by a relatively longer latency of cortical inhibition than excitation in muscles innervated below the injury. ${ }^{8}$ We propose that the reduction in strength of intracortical inhibition will facilitate corticospinal output and so aid voluntary motor function. However, the timing of the electrophysiological changes relative to the observed recovery of function presents a paradox. This study shows that the change in inhibition occurs very soon (probably within days) after injury but recovery of function continues over a year post-injury. A major aim of future work will be to test the hypothesis that weakened corticospinal inhibition or enhanced facilitation is important in determining motor recovery after iSCI.

Two imaging studies carried out by this laboratory have supported the notion of reorganisation at a cortical level following iSCI.

(1) Proton magnetic resonance spectroscopy (MRS) has shown that $\mathrm{N}$-acetylaspartate (NAA) levels are increased in the motor cortices of patients who have shown good recovery following iSCI. ${ }^{11}$ NAA is a marker of neuronal function. Its level in the cortex doubles during cortical development in the first year of $\operatorname{life}^{18}$ and falls in a number of neurodegenerative conditions such as Huntington's disease. ${ }^{19}$ Increased NAA following iSCI might reflect motor cortical reorganisation as a result of having to re-learn motor skills.

(2) Davey et $a l^{12}$ have recently completed a preliminary investigation using positron emission tomography (PET) and radio ligands comparing levels of the inhibitory neurotransmitter gamma aminobutyric acid (GABA) in iSCI and controls. The results suggest reduced GABA activity in the motor cortices of iSCI patients supporting the hypothesis that intracortical inhibition is reduced.

The degree and extent of the injury is the primary determinant of the degree of recovery. The question then arises whether physiotherapy or occupational therapy or the individual's personal effort play a role in cortical reorganisation. If the early cortical changes are responsible for facilitating the ability to recover motor function then the precise timing of any rehabilitation therapy would be important. Ziemann et $a l^{20,21}$ have shown that both intracortical inhibition and facilitation can be modulated by altering the afferent feedback to the cortex, using ischaemic nerve blocks, with drugs and with repetitive TMS (rTMS). Such interventions may be developed to try to improve recovery by allowing enhancement of beneficial changes or reduction of maladaptive changes in the natural processes that reorganise cortical function following iSCI.

\section{Acknowledgements}

The Wellcome Trust supported this study. We thank Staff Nurses Anne McCreath and Cherry Gregory for their help. We would like to thank patients and staff at the National Spinal Injuries Centre, Stoke Mandeville Hospital for participating in and helping with this study.

\section{References}

1 Maynard Jr MF et al. International standards for neurological functional classification of spinal cord injury. Spinal Cord 1997; 35: $266-274$

2 Asazuma T et al. Management of patients with incomplete spinal cord injury. Spinal Cord 1996; 34: 620-625.

3 Gianutsos $\mathrm{J}$ et al. A noninvasive technique to assess completeness of spinal cord lesions in humans. Exp Neurol 1987; 98: 34-40.

4 Clarke CE, Modarres-Sadeghi H, Twomey JA, Burt AA. Prognostic value of cortical magnetic stimulation in spinal cord injury. Paraplegia 1994; 32: 554-560.

5 Bondurant CP, Haghighi SS. Experience with transcranial magnetic stimulation in evaluation of spinal cord injury. Neurol Res 1997; 19: $497-500$.

6 McKay WB, Stokic DS, Dimitrijevic MR. Assessment of corticospinal function in spinal cord injury using transcranial magnetic stimulation: a review. J Neurotrauma 1997; 14: $539-$ 548

7 Kirshblum SC, O'Connor KC. Predicting neurologic recovery in traumatic cervical spinal cord injury. Arch Phys Med Rehabil 1998; 79: 1456 - 1466.

8 Davey NJ et al. Responses of thenar muscles to transcranial magnetic stimulation of the motor cortex in incomplete spinal cord injury patients. J Neurol Neurosurg Psychiatry 1998; 65: $80-87$.

9 Davey NJ et al. Comparison of input-output patients in the corticospinal system of normal subjects and incomplete spinal cord injured patients. Exp Brain Res 1999; 127: $382-390$. 
10 Davey NJ, Romaiguère P, Maskill DW, Ellaway PH. Suppression of voluntary motor activity revealed using transcranial magnetic stimulation of the motor cortex in man. J Physiol 1994; 477: $223-235$.

11 Puri BK et al. The human motor cortex following incomplete spinal cord injury: an investigation using proton magnetic resonance spectroscopy. J Neurol Neurosurg Psychiatry 1998; 65: $748-754$.

12 Davey NJ et al. A ${ }^{11} \mathrm{C}$-flumazenil positron emission tomography (PET) study to determine GABAergic cortical changes in the motor cortex following incomplete spinal cord injury (iSCI) in humans. Abst Soc Neurosci 1999; 25; 603.6.

13 Smith HC, Davey NJ, Savic G, Ellaway PH. Corticospinal function following incomplete spinal cord injury: changes over time. Abst Soc Neurosci 1998; 24: 653.6.

14 Day BL et al. Direction of current in magnetic stimulating coils used for percutaneous activation of brain, spinal cord and peripheral nerve. J Physiol 1990; 430: 617.

15 Rossini PM et al. Non-invasive electrical and magnetic stimulation of the brain, spinal cord and roots: basic principles and procedures for routine clinical application. Report of an IFCN committee. Electroencephalog Clin Neurophysiol 1994; 91: $79-92$.
16 Widmer CG, Lund JP. Evidence that peaks in EMG averages can sometimes be caused by inhibition of motoneurones. $J$ Neurophysiol 1989; 62: 212-219.

17 Alexeeva N, Broton JG, Calancie B. Latency changes in spinal motoneurone excitability evoked by transcranial magnetic stimulation in spinal cord injured individuals. Electroencephalog Clin Neurophysiol 1998; 109: 297-303.

18 van der Knapp MS et al. Age-dependent changes in localized proton and phosphorus MR spectroscopy of the brain. Radiology 1990; 176: $509-515$.

19 Harms L et al. Decreased N-acetyl-aspartate/choline ratio and increased lactate in the frontal lobe of patients with Huntington's disease: a proton magnetic resonance spectroscopy study. $J$ Neurol Neurosurg Psychiatry 1997; 62: $27-30$.

20 Ziemann U, Corwell B, Cohen LG. Modulation of plasticity in human motor cortex after forearm ischemic nerve block. $J$ Neurosci 1998; 18: 1115-1123.

21 Ziemann U, Hallett M, Cohen LG. Mechanisms of deafferentation-induced plasticity in human motor cortex. J Neurosci 1998; 18: $7000-7007$. 